\title{
STUDI TEMPORAL KOMUNITAS IKAN KARANG (2014-2018) PADA PERAIRAN KECAMATAN MESJID RAYA DAN PEUKAN BADA, KABUPATEN ACEH BESAR
}

\section{TEMPORAL STUDY OF REEF FISH COMMUNITIES (2014-2018) WATER OF MESJID RAYA SUB-DISTRICT AND PEUKAN BADA, ACEH BESAR DISTRICT}

\author{
Maria Ulfah ${ }^{1,3 *}$, M. Rizki Fazillah ${ }^{2}$, Iqbal Nindo Turnip ${ }^{2}$, \& Aprilina Seragih ${ }^{2}$ \\ ${ }^{1}$ Program Studi Ilmu Kelautan, FKP-Unsyiah, Banda Aceh, 23111, Indonesia \\ ${ }^{2}$ Ocean Diving Club, FKP- Unsyiah, Banda Aceh, 23111, Indonesia \\ ${ }^{3}$ Laboratorium Biologi Laut, FKP- Unsyiah, Banda Aceh, 23111, Indonesia \\ *E-mail: mariaulfah@unsyiah.ac.id
}

\begin{abstract}
Reef fishes are the group of fish that have a high association with the coral reef ecosystem as spawning, nursery, and feeding grounds. This study aims to determine the reef fish community through the approach of abundance, diversity, uniformity, and dominance of reef fish in 2014-2018 in the waters of the Mesjid Raya Sub-district and Peukan Bada, Aceh Besar District. This research was carried out from 2014 to 2018, with research locations, there are 8 locations. Reef fish data collection was carried out using the underwater visual census (UVC). The total species of reef fish found during 2014-2018 were 115 species from 39 families. The waters of Mesjid Raya sub-district have the lowest abundance of reef fish with a number of 128 ind/ha in 2014 observations in Lhok Mee waters and the highest abundance of fish as much as 80 ind/ha in the waters of Fort Inong Balee in 2017. It is different from sub-district waters Peukan Bada has an abundance of reef fish with the lowest value of 96 ind/ha in 2014 observations in the waters of Lhok Mata Ie and reached the highest value of 2401.70 ind/ha in the same waters in 2018. Results of the average ecological index value Reef fish in the District of Mesjid Raya and Peukan Bada in 2014-2018 did not have a significant difference.
\end{abstract}

Keywords: Aceh Besar, abundance, community, ecology index, reef fish

\begin{abstract}
ABSTRAK
Ikan karang merupakan ikan yang memanfaatkan ekosistem terumbu karang sebagai tempat tinggal, mencari makan, memijah dan pengasuhan. Penelitian ini bertujuan untuk mengetahui komunitas ikan karang melalui pendekatan kelimpahan, keanekaragaman, keseragaman dan dominansi ikan karang pada tahun 2014-2018 di perairan Kecamatan Mesjid Raya dan Peukan Bada, Kabupaten Aceh Besar. Penelitian ini dilaksanakan dari tahun 2014 hingga tahun 2018, dengan lokasi penelitian ada 8 lokasi. Pengambilan data ikan karang dilakukan dengan menggunakan metode underwater visual cencus (UVC). Total spesies ikan karang yang ditemukan selama tahun 2014 dan 2018 adalah sebanyak 115 spesies dari 39 famili. Perairan Kecamatan Mesjid Raya memiliki nilai kelimpahan ikan karang terendah sejumlah 128 ind/ha pada pengamatan tahun 2014 di perairan Lhok Mee dan kelimpahan ikan tertinggi sejumlah 796 ind/ha di perairan Benteng Inong Balee tahun 2017. Sedangkan perairan Kecamatan Peukan Bada memiliki kelimpahan ikan karang dengan nilai terendah sejumlah 96 ind/ha pada pengamatan tahun 2014 di perairan Lhok Mata Ie dan mencapai nilai tertinggi sejumlah 2401,70 ind/ha di perairan yang sama tahun 2018. Hasil rata-rata nilai indeks ekologi ikan karang di Kecamatan Mesjid Raya dan Peukan Bada tahun 2014-2018 tidak memiliki perbedaan yang signifikan.
\end{abstract}

Kata kunci: Aceh Besar, ikan karang, indeks ekologi, kelimpahan, komunitas 


\section{PENDAHULUAN}

Ikan karang merupakan taksa terbesar dari kelompok vertebrata yang berasosiasi dengan terumbu karang (Hill \& Wilkinson, 2004). Ikan karang hidup pada daerah terumbu karang sejak dari masa juvenil hingga dewasa. Terumbu karang merupakan salah satu ekosistem laut yang sangat penting. Perannya dimanfaatkan oleh organisme penghuni terumbu karang khususnya ikan karang sebagai tempat hidup, berlindung, mencari makan, dan berkembang biak. Salah satu indikator kesehatan terumbu karang adalah komunitas ikan karang di perairan tersebut. Keberadaan ikan di daerah terumbu karang sangat tergantung pada kondisi terumbu karang itu sendiri (Madduppa, 2006).

Kerusakan ekosistem terumbu karang akan memberikan pengaruh tidak hanya berupa penurunan keragaman hayati, tetapi juga berdampak pada sosial ekonomi bagi masyarakat pesisir (nelayan). Oleh karena itu, diperlukan kegiatan regulasi terkait dengan usaha agar dapat membatasi kerusakan tersebut serta melakukan restorasi terhadap terumbu karang yang rusak. Berdasarkan analisis terhadap ancamanancaman potensial bagi terumbu karang akibat aktivitas manusia (seperti pembangunan daerah pesisir, eksploitasi berlebihan, praktik perikanan yang merusak, erosi dan pencemaran), diperkirakan sekitar $27 \%$ dari terumbu karang dunia berada pada resiko tinggi dan $31 \%$ lainnya berada dalam resiko sedang (Bryant et al., 1998).

Sejauh ini penelitian terkait komunitas ikan karang di Aceh khususnya Kabupaten Aceh Besar masih sangat sedikit dilakukan dan dipublikasi. Beberapa penelitian terkait komunitas ikan karang yang pernah dilakukan di perairan Kabupaten Aceh Besar diantaranya oleh Rudi et al. (2009); Rudi \& Fadli (2012); Edrus et al. (2013) dan Nasir et al. (2017). Kajian secara temporal komunitas ikan karang belum pernah dikaji di Aceh dan hanya sedikit yang pernah dilaporkan di Indonesia (Johnson et al., 2018). Penelitian ini perlu dilakukan, dengan adanya data informasi selama 5 tahun tentang struktur komunitas ikan karang, diharapkan dapat memberikan informasi terbaru dan masukan sebagai pertimbangan dalam membuat perencanaan, pengembangan, dan pengelolaan kawasan perairan tersebut. Tujuan dari penelitian ini adalah untuk mengetahui komunitas ikan karang melalui pendekatan kelimpahan, keanekaragaman, keseragaman dan dominansi ikan karang pada tahun 2014-2018 di perairan Kecamatan Mesjid Raya dan Peukan Bada, Kabupaten Aceh Besar.

\section{METODE PENELITIAN}

\subsection{Waktu dan Lokasi}

Pengambilan data dilakukan dari tahun 2014 hingga 2018 setiap bulan Oktober. Adapun lokasi penelitian terdiri dari 8 stasiun yang meliputi perairan Kecamatan Mesjid Raya (stasiun 1. Lhok Mee, stasiun 2. Ahmad Rhang Manyang, stasiun 3. Benteng Inong Balee) dan perairan Kecamatan Peukan Bada (stasiun 4. Pulau Tuan, stasiun 5. Lhok Mata Ie, stasiun 6. Lhok Keutapang, stasiun 7. Pulau Batee Timur, stasiun 8. Pulau Batee Barat). Lokasi penelitian tercantum pada (Figure 1).

\subsection{Alat dan Bahan}

Alat dan bahan utama yang digunakan dalam penelitian ini adalah peralatan $S C U B A$, roll $\mathrm{m}(100 \mathrm{~m})$, alat tulis bawah air, kamera bawah air dan buku identifikasi ikan karang referensi dari Allen et al. (2003); Kuiter \& Tonozuka (2001); Rudi \& Muchlisin (2010).

\subsection{Pengambilan Data}

Pengambilan data ikan karang dilakukan dengan menggunakan metode UVC-belt transect. Pengamatan dilakukan sepanjang $20 \mathrm{~m}$ dengan ulangan empat kali, antara transek diberi jeda $5 \mathrm{~m}$ dengan transek berikutnya. Terdapat dua kedalaman berbeda 

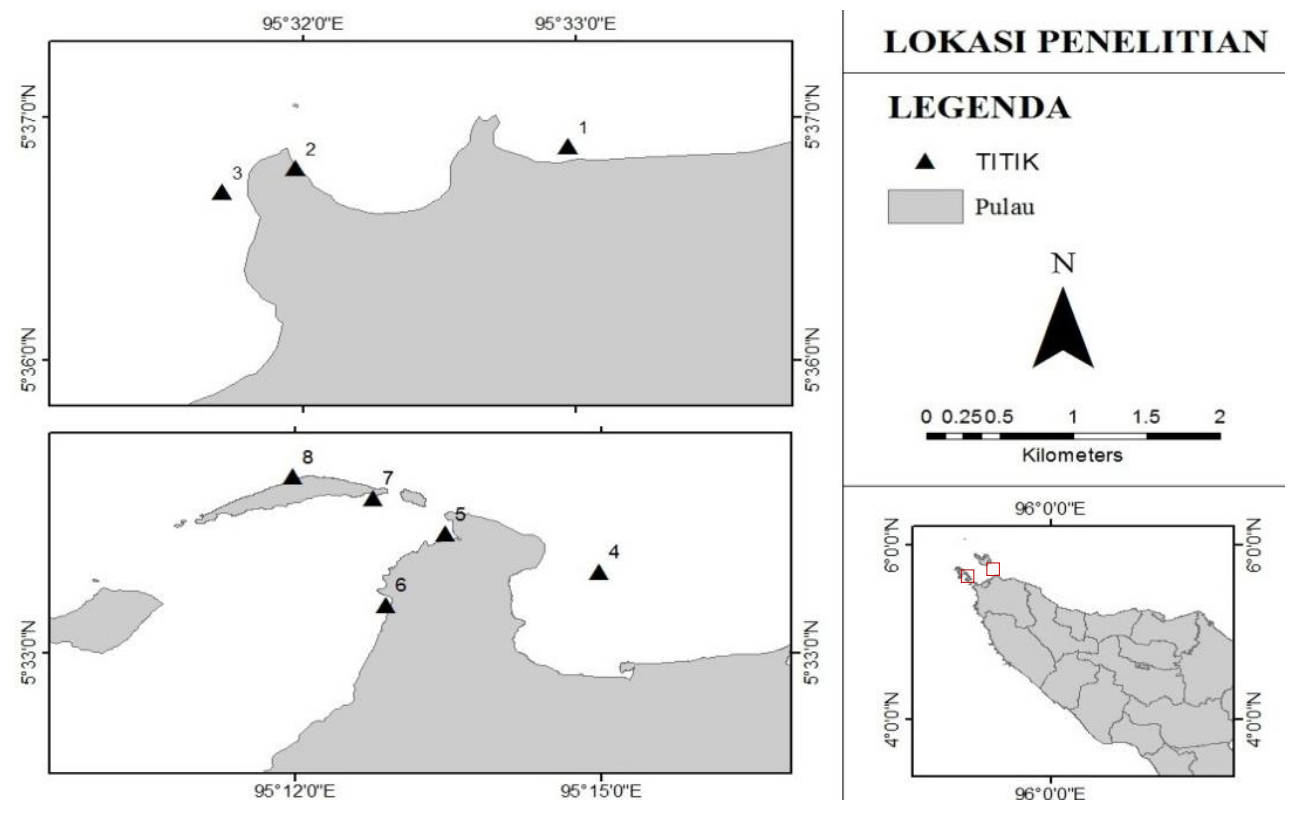

Figure 1. Map of Water Research Location in Mesjid Raya and Pukan Bada sub-districts (Site 1. Lhok Me; Site 2. Ahmad Rhang Manyang; Site 3. Benteng Inong Bale; Site 4. Pulau Tuan; Site 5. Lhok Mata Ie; Site 6. Lhok Ketapang; Site 7. East Pulau Bate and Site 8. West Pulau Bate).

dalam pengambilan data, yaitu dangkal (0-6 m) dalam (6-12 m). Pengamatan dilakukan dengan mengamati ikan sejauh 2,5 m bagian kanan dan kiri untuk ikan berukuran lebih besar dari $10 \mathrm{~cm}$, dan mengamati ikan sejauh $1 \mathrm{~m}$ bagian kanan dan kiri untuk ikan berukuran lebih kecil dari $10 \mathrm{~cm}$ (English et al., 1994).

\subsection{Analisis Data}

\subsubsection{Kelimpahan Ikan Karang}

Banyaknya individu ikan persatuan volume daerah pengamatan ditunjukkan oleh nilai kelimpahan ikan. Rumus kelimpahan ikan adalah sebagai berikut (Odum, 1993):

$\mathrm{X}_{\mathrm{i}}=\frac{\mathrm{n}_{\mathrm{i}}}{\mathrm{A}}$

Keterangan: $\mathrm{X}_{\mathrm{i}}=$ kelimpahan ikan karang (ind/ ha), $\mathrm{n}_{\mathrm{i}}=$ jumlah total komunitas ikan ke$\mathrm{i}(\mathrm{cm})$, dan $\mathrm{A}=$ luas transek pengamatan (ha).

\subsubsection{Indeks Keanekaragaman (H')}

Indeks keanekaragaman

menyatakan keadaan populasi organisme secara matematis agar mempermudah dalam menganalisis informasi jumlah individu. Indeks keanekaragaman yang digunakan adalah indeks Shannon-Weiner (Krebs, 1989) dengan persamaan:

$\mathrm{H}^{0}=-\sum_{\mathrm{i}=1}^{\mathrm{s}} \mathrm{P}_{\mathrm{i}} \ln \mathrm{P}_{\mathrm{i}}$

Keterangan: H'= indeks keanekaragaman, $\mathrm{P}_{\mathrm{i}}=$ proporsi jumlah individu pada suatu biota, $s=$ jumlah biota.

\subsubsection{Indeks Keseragaman (E)}

Indeks keseragaman (E) menggambarkan jumlah individu antar spesies dalam suatu komunitas ikan. Semakin merata penyebaran individu antar spesies maka keseimbangan ekosistem akan semakin meningkat. Indeks keseragaman menggambarkan sebaran jumlah individu antar spesies dalam suatu komunitas ikan merata atau tidak. Semakin merata penyebaran individu antar spesies maka keseimbangan ekosistem akan semakin meningkat. Nilai indeks keseragaman memiliki kisaran 0-1 dengan kategori komunitas tertekan $(0,0<\mathrm{E}$ 
$\leq 0,5)$, komunitas labil $(0,5<\mathrm{E} \leq 0,75)$, dan komunitas stabil $(0,75<\mathrm{E} \leq 1)$. Rumus indeks keseragaman adalah sebagai berikut (Odum, 1993):

$\mathrm{E}=\frac{\mathrm{H}^{\mathrm{P}}}{\mathrm{H} \max }$

Keterangan: $\mathrm{E}=$ indeks keseragaman, $\mathrm{H}^{\prime}=$ indeks keanekaragaman, dan H' max= indeks keanekaragaman maksimum.

\subsubsection{Indeks Dominansi}

Nilai indeks keanekaragaman dan keseragaman yang kecil menandakan adanya dominansi yang tinggi suatu spesies terhadap spesies-spesies lainnya. Indeks dominansi (C) menunjukkan kelimpahan ikan didominasi oleh beberapa spesies atau tidak. Nilai indeks dominansi memiliki kisaran 0-1 dengan kategori dominasi rendah $(0,0<\mathrm{D} \leq$ $0,5)$, dominasi sedang $(0,5<\mathrm{D} \leq 0,75)$, dan dominasi tinggi $(0,75<\mathrm{D} \leq 1)$. Rumus indeks dominansi adalah sebagai berikut (Odum,1993):

$\mathrm{D}=\sum_{\substack{\mathrm{i} \\=1}}^{\mathrm{s}} \mathrm{pi}^{2}$

Keterangan: $\mathrm{D}=$ indeks dominansi, $\mathrm{s}=$ jumlah biota dan $\mathrm{pi}=$ proporsi jumlah individu pada suatu biota.

\section{HASIL DAN PEMBAHASAN}

\subsection{Kelimpahan Ikan Karang}

Secara umum jumlah famili ikan karang pada perairan Aceh Besar sejak tahun 2014 hingga tahun 2018 mengalami fluktuatif yang cukup tinggi. Total jumlah spesies ikan karang yang ditemukan sebanyak 115 spesies dari 39 famili. Kelimpahan ikan karang bergantung dengan kondisi habitat dan dipengaruhi oleh aktivitas penangkapan manusia. Hasil pemantauan selama 5 tahun pada rata-rata kedalaman dari tahun 2014-2018 menunjukkan nilai kelimpahan ikan yang berbeda secara signifikan antara Kecamatan Mesjid Raya dan Peukan Bada (Figure 2 dan Figure 3). Secara keseluruhan perairan Kecamatan Peukan Bada memiliki nilai kelimpahan ikan karang yang lebih tinggi dibandingkan dengan perairan Kecamatan Mesjid Raya.

Perairan Benteng Inong Balee mempunyai kelimpahan ikan karang yang paling banyak di Kecamatan Mesjid Raya. Meskipun nilai kelimpahan ikan karang menurun pada tahun 2015, selanjutnya kembali naik hingga kelimpahan ikan mencapai nilai sebesar 795,59 ind/ha pada tahun 2017. Perairan Ahmad Rhang Manyang memiliki nilai kelimpahan ikan karang yang berangsur naik tiap tahunnya dengan nilai sejumlah 127,88 hingga 769,91 ind/ha. Akan tetapi pada pemantauan tahun 2018 nilai kelimpahan ikan karang di perairan Ahmad Rhang Manyang turun dengan nilai sebesar 344,88 ind/ha. Perairan Lhok Mee mempunyai kelimpahan ikan karang yang paling sedikit dibandingkan dengan kedua lokasi lainnya di Kecamatan Mesjid Raya. Tahun 2014 kelimpahan ikan karang di Perairan Lhok Mee hanya 172,94 ind/ha, selanjutnya nilai kelimpahan naik dengan bertahap tiap tahunnya hingga mencapai 617,04 ind/ha pada tahun 2018.

Rendahnya nilai kelimpahan ikan di perairan Kecamatan Mesjid Raya diduga karena terjadinya perubahan habitat terumbu karang yang telah rusak diakibatkan oleh gangguan faktor alam maupun faktor manusia. Faktor alam yaitu terjadinya pemutihan karang Aceh pada tahun 2010 dan faktor manusia seperti penangkapan sumberdaya ikan yang tidak ramah lingkungan di daerah tersebut (Octavina et al., 2018 dan Ulfah et al., 2018). Menurut Halford et al. (2004) dan Ulfah et al. (2018) perubahan yang terjadi pada habitat dan fungsi ikan pada habitatnya akan memperlihatkan perubahan struktur komunitas ikan dari lokasi ke lokasi, juga respon ikan pada perubahan habitat pada umumnya dihubungkan pada tipe mikro habitat yang hilang dan degradasi tutupan terumbu karang. Hieske \& Myers (2001) menyatakan 
bahwa ikan karang sebagai suatu komunitas memiliki habitat yang berbeda tetapi banyak spesies yang terdapat pada lebih dari satu habitat. Umumnya tiap spesies ikan karang yang mendiami suatu perairan memiliki kesukaan habitat tertentu, setiap habitat didiami oleh spesies dengan karakteristik yang khas.

Perairan Lhok Mata Ie mempunyai kelimpahan ikan karang yang paling banyak dibandingkan dengan lokasi pemantauan lainnya di Kecamatan Peukan Bada. Kelimpahan ikan selalu naik dengan signifikan tiap tahunnya, sejak pemantauan tahun 2014 hanya memiliki nilai kelimpahan 95,74 ind/ha hingga tahun 2018 mencapai nilai kelimpahan sebesar 2401,69 ind/ha. Pada perairan ini kondisi rata-rata persentase tutupan karang hidup masuk kedalam katagori baik dengan nilai persentase tutupan mencapai $66 \%$. Hal ini menyebabkan tingginya kelimpahan ikan karang pada perairan Lhok Mata Ie. Menurut Nasir et al. (2017) kondisi terumbu karang yang berbeda berpengaruh terhadap ketersediaan sumber makanan bagi ikan karang.

Perairan Pulau Tuan memiliki nilai kelimpahan ikan karang yang paling sedikit dibandingkan dengan lokasi lainnya di Kecamatan Peukan Bada. Meskipun pemantauan tahun 2016 nilai kelimpahan ikan karang naik dengan drastis hingga mencapai 1499,99 ind/ha, namun pemantauan tahun berikutnya turun kembali dengan drastis hingga mencapai 281,74 ind/ha tahun 2018. Rendahnya kelimpahan pada perairan ini diduga disebabkan oleh menurunnya persentase tutupan karang hidup dengan nilai rata-rata tutupan sebesar 37,56\% dengan kategori sedang. Hal ini sesuai dengan pernyataan Muniaha et al. (2016) yang menyatakan bahwa perbedaan persentase tutupan karang hidup dapat mempengaruh kelangsungan kehidupan ikan karang.

Perairan Lhok Keutapang dan Pulau Batee Barat dimulai pemantauan sejak tahun 2015. Dari awal pemantauan hingga tahun 2017 perairan Lhok Keutapang memiliki nilai kelimpahan ikan karang yang meningkat drastis hingga mencapai 1985,28 ind/ha. Sedangkan perairan Pulau Batee Barat sejak awal pemantauan hingga tahun 2017 nilai kelimpahan ikan karang naik perlahan hingga sejumlah 630,11 ind/ha, lalu pada akhir pemantauan tahun 2018 turun kembali menjadi 281,74 ind/ha. Hal ini tidak jauh berbeda dengan perairan Pulau Batee Barat, pemantauan pada perairan Pulau Batee Timur nilai kelimpahan ikan karang naik dengan perlahan tiap tahunnya hingga mencapai 909,43 ind/ha pada tahun 2018.

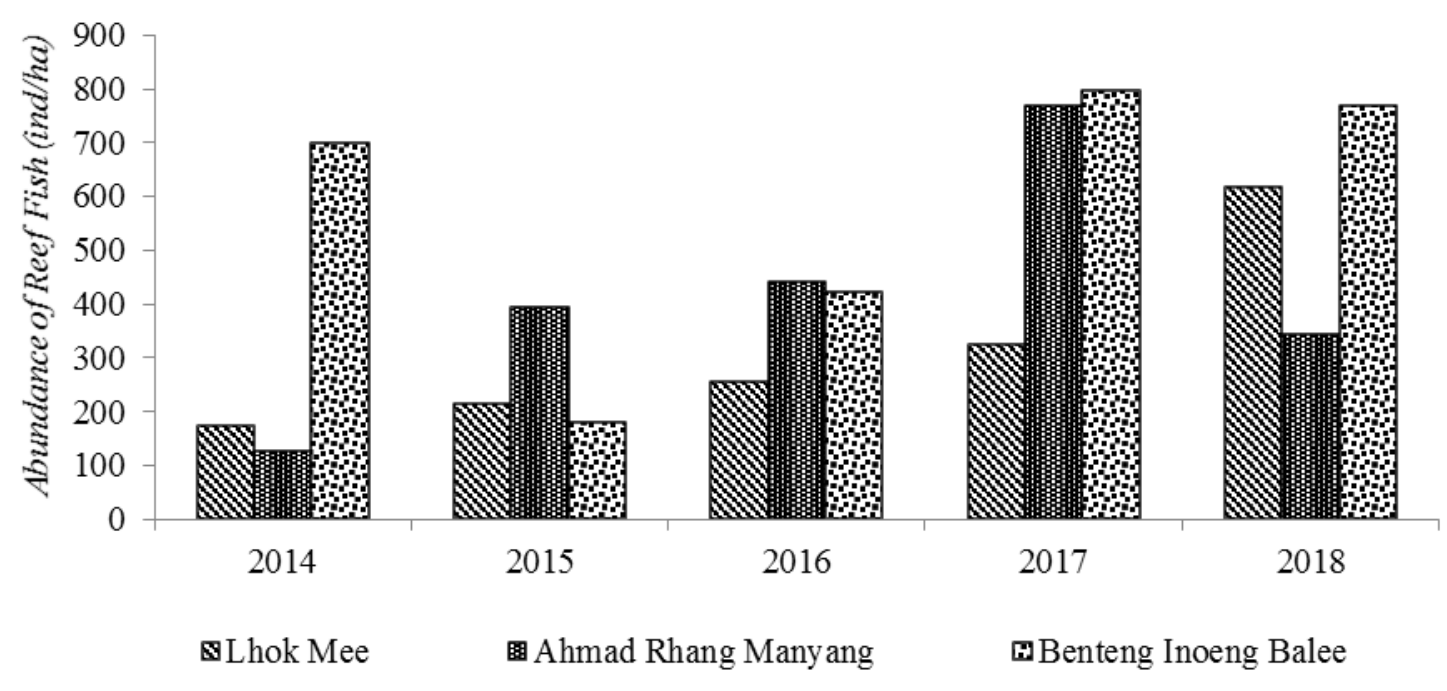

Figure 2. Graph of the abundance of reef fish in Mesjid Raya sub-district in 2014-2018. 


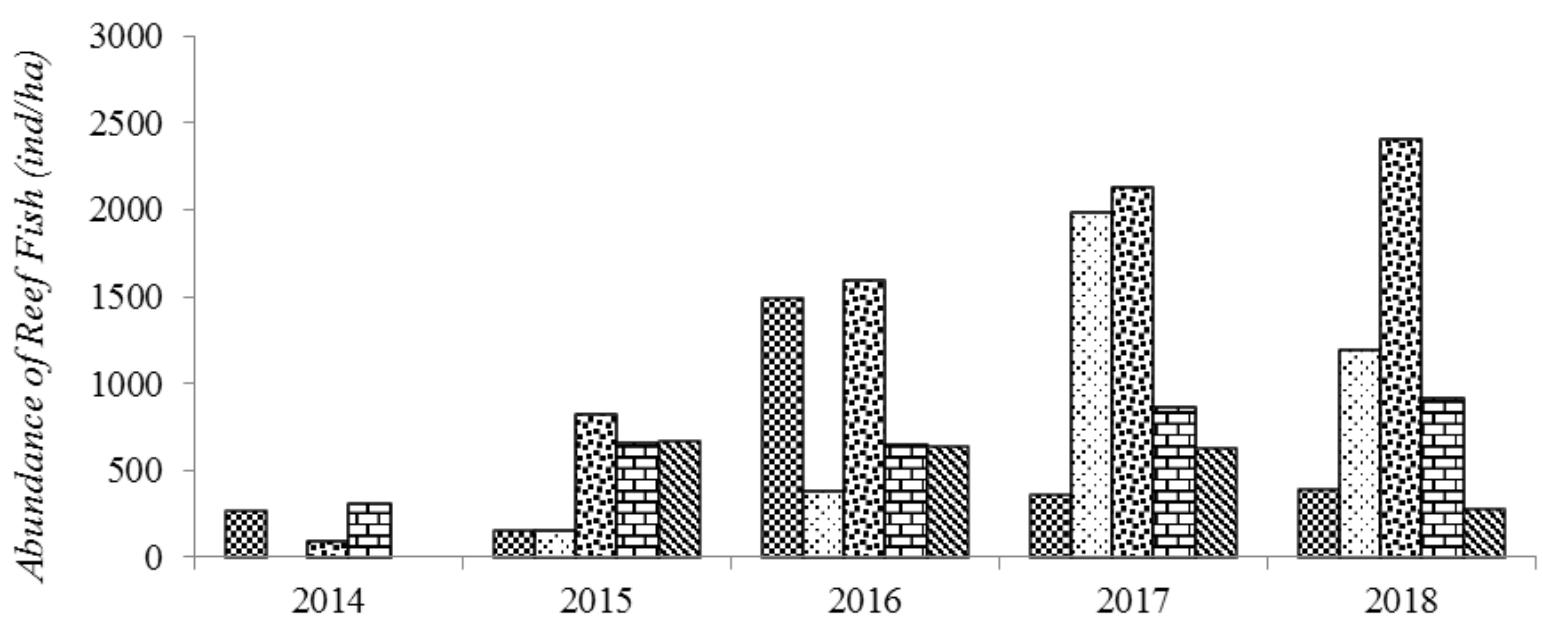

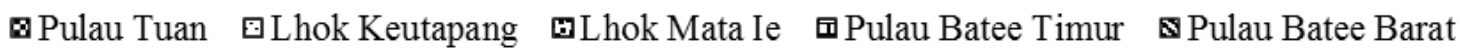

Figure 3. Graph of the abundance of reef fish in Peukan Bada sub-district in 2014-2018.

Secara keseluruhan perairan Kecamatan Mesjid Raya memiliki nilai kelimpahan ikan karang terendah sejumlah $127,87 \mathrm{ind} / \mathrm{ha}$ pada pengamatan tahun 2014 di perairan Lhok Mee dan kelimpahan ikan tertinggi sejumlah 795,59 ind/ha di perairan Benteng Inong Balee tahun 2017. Hal ini berbeda dengan perairan Kecamatan Peukan Bada memiliki kelimpahan ikan karang dengan nilai terendah sejumlah $95,74 \mathrm{ind} / \mathrm{ha}$ pada pengamatan tahun 2014 di perairan Lhok Mata Ie dan mencapai nilai tertinggi sejumlah $2401,70 \mathrm{ind} / \mathrm{ha}$ di perairan yang sama tahun 2018.

\subsection{Keanekaragaman Ikan Karang (H')}

Indeks keanekaragaman ikan karang merupakan perameter untuk menilai besar kecilnya keanekaragaman suatu jenis dalam satu lokasi pengamatan. Nilai indeks keanekaragaman memiliki kategori kriteria keanekaragaman rendah $\left(\mathrm{H}^{\prime} \leq 3\right)$, keanekaragaman sedang $\left(1<\mathrm{H}^{\prime} \leq 3\right)$ dan keanekaragaman tinggi $\left(\mathrm{H}^{\prime} \geq 3\right)$. Nilai indeks keanekaragaman ikan karang di Kecamatan Mesjid Raya dan Peukan Bada tahun 20142018 tercantum pada Table 1.

Secara keseluruhan rata-rata nilai indeks keanekaragaman ikan karang di Kecamatan Mesjid Raya dan Peukan Bada tahun 2014-2018 tidak memiliki perbedaan yang signifikan. Hasil analisis indeks keanekaragaman ikan karang di perairan Kecamatan Mesjid Raya berkisar antara 2,532,76 dan Kecamatan Peukan Bada bernilai 1,98-2,63 keduanya digolongkan dalam kategori keanekaragaman sedang (Table 2).

Hal ini tidak jauh berbeda dengan hasil penelitian yang dilakukan Edrus et al. (2013) di Pulau Raya. Pulau Rusa dan Pulau Rondo memiliki nilai indeks keanekaragaman ikan karang berkisar 2,33-2,95 dengan kategori keanekaragaman sedang. Akan tetapi dalam penelitian yang sama namun dengan lokasi yang berbeda yaitu di perairan Desa Rinoi dan Rubiah yang dianggap sebagai taman laut diperoleh hasil berbeda dengan nilai indeks keanekaragaman ikan karang berkisar 3,15-3,23 termasuk dalam kategori keanekaragaman yang tinggi.

\subsection{Keseragaman Ikan Karang}

Nilai indeks keseragaman ikan karang di Kecamatan Mesjid Raya dan Peukan Bada tahun 2014-2018 tercantum pada Table 2.

Secara keseluruhan rata-rata nilai indeks keseragaman ikan karang di Kecamatan Mesjid Raya dan Peukan Bada tahun 2014-2018 tidak memiliki perbedaan yang signifikan. Nilai indeks keseragaman ikan karang yang diperoleh di perairan 
Kecamatan Mesjid Raya berkisar antara 0,480,52 dan Kecamatan Peukan Bada berkisar dengan nilai 0,37-0,50 dalam hal ini keduanya digolongkan dalam kategori komunitas yang tertekan (Table 3).

\subsection{Dominansi Ikan Karang}

Nilai indeks dominansi ikan karang di Kecamatan Mesjid Raya dan Peukan Bada tahun 2014-2018 tercantum pada Table 3.

Secara keseluruhan rata-rata nilai indeks dominansi ikan karang di Kecamatan Mesjid Raya dan Peukan Bada tahun 20142018 hanya sedikit perbedaan. Hasil perhitungan indeks dominansi ikan karang di perairan Kecamatan Mesjid Raya bernilai 0,1 dan Kecamatan Peukan Bada bernilai 0,1-0,3 dimana keduanya termasuk dalam kategori dominansi rendah (Table 4).

Ikan karang memberikan petunjuk atau merespon adanya gangguan pada habitatnya sesuai intensitas pengaruhnya. Gangguan pada habitatnya dapat terjadi di suatu lokasi. yang mungkin saja sudah berlangsung lama atau datang mendadak. Gangguan tersebut berpengaruh dalam intensitas yang berbeda dari suatu lokasi ke lokasi yang lain. hingga menciptakan kondisi tertentu yang direspon berbeda dengan komunitas ikan karang seperti yang ditunjukkan oleh nilai indeks ekologi (Edrus et al., 2013).

Table 1. Presence frequency of reef fish family during 2014-2018 (Site 1. Lhok Me; Site 2. Ahmad Rhang Manyang; Site 3. Benteng Inong Bale; Site 4. Pulau Tuan; Site 5. Lhok Mata Ie; Site 6. Lhok Ketapang; Site 7. East Pulau Bate and Site 8. West Pulau Bate).

\begin{tabular}{lcccccccc}
\hline \multicolumn{1}{c}{ Family } & Site 1 & Site 2 & Site 3 & Site 4 & Site 5 & Site 6 & Site 7 & Site 8 \\
\hline Acanthuridae & 2.11 & 1.76 & 2.35 & 2.38 & 1.62 & 2.72 & 2.96 & 2.84 \\
Anthiinae & 0.10 & 0.00 & 0.07 & 0.00 & 0.02 & 0.07 & 0.25 & 0.00 \\
Apogonidae & 0.00 & 0.00 & 0.02 & 0.00 & 0.00 & 0.00 & 0.00 & 0.00 \\
Aulostomidae & 0.00 & 0.12 & 0.02 & 0.10 & 0.02 & 0.10 & 0.05 & 0.00 \\
Balistidae & 0.05 & 0.00 & 0.10 & 0.02 & 0.10 & 0.00 & 0.10 & 0.02 \\
Batrachoididae & 0.00 & 0.00 & 0.00 & 0.02 & 0.00 & 0.00 & 0.00 & 0.00 \\
Caesionidae & 0.22 & 0.07 & 0.20 & 0.15 & 0.10 & 0.17 & 0.00 & 0.20 \\
Carangidae & 0.05 & 0.00 & 0.00 & 0.02 & 0.05 & 0.00 & 0.00 & 0.02 \\
Centriscidae & 0.00 & 0.02 & 0.12 & 0.02 & 0.00 & 0.00 & 0.00 & 0.00 \\
Chaetodontidae & 2.16 & 1.86 & 3.06 & 2.38 & 2.55 & 2.47 & 3.04 & 2.28 \\
Creediidae & 0.00 & 0.00 & 0.00 & 0.12 & 0.00 & 0.00 & 0.00 & 0.00 \\
Dasyatidae & 0.02 & 0.00 & 0.00 & 0.00 & 0.00 & 0.00 & 0.00 & 0.00 \\
Ephippidae & 0.00 & 0.00 & 0.00 & 0.02 & 0.00 & 0.00 & 0.00 & 0.00 \\
Fistulariidae & 0.02 & 0.05 & 0.00 & 0.00 & 0.02 & 0.02 & 0.00 & 0.00 \\
Gobidae & 0.00 & 0.00 & 0.10 & 0.00 & 0.00 & 0.05 & 0.00 & 0.00 \\
Haemulidae & 0.07 & 0.12 & 0.29 & 0.25 & 0.32 & 0.20 & 0.12 & 0.32 \\
Holocentridae & 0.15 & 0.37 & 0.02 & 0.54 & 0.42 & 0.05 & 0.32 & 0.37 \\
Kyphosidae & 0.00 & 0.00 & 0.15 & 0.00 & 0.00 & 0.00 & 0.20 & 0.00 \\
Labridae & 1.15 & 0.96 & 0.91 & 0.96 & 0.81 & 0.96 & 1.20 & 1.25 \\
Lutjanidae & 0.20 & 0.17 & 0.29 & 0.44 & 0.27 & 0.12 & 0.17 & 0.00 \\
Mullidae & 0.17 & 0.27 & 0.44 & 0.17 & 0.05 & 0.07 & 0.12 & 0.20 \\
Muraenidae & 0.02 & 0.00 & 0.05 & 0.02 & 0.00 & 0.05 & 0.00 & 0.00 \\
Nemipteridae & 0.88 & 0.15 & 0.42 & 0.20 & 0.27 & 0.22 & 0.27 & 0.34 \\
Ostracidae & 0.00 & 0.00 & 0.00 & 0.00 & 0.00 & 0.05 & 0.02 & 0.00 \\
Pempheridae & 0.15 & 1.23 & 0.05 & 0.27 & 0.15 & 0.15 & 0.02 & 0.17 \\
\hline & & & & & & & &
\end{tabular}




\begin{tabular}{lcccccccc}
\hline \multicolumn{1}{c}{ Family } & Site 1 & Site 2 & Site 3 & Site 4 & Site 5 & Site 6 & Site 7 & Site 8 \\
\hline Pempherididae & 0.00 & 0.00 & 0.00 & 0.00 & 0.00 & 0.02 & 0.00 & 0.00 \\
pinguipedidae & 0.25 & 0.00 & 0.05 & 0.05 & 0.00 & 0.07 & 0.00 & 0.00 \\
Plotosidae & 0.00 & 0.02 & 0.00 & 0.00 & 0.00 & 0.00 & 0.00 & 0.00 \\
Pomacanthidae & 0.37 & 0.61 & 0.29 & 0.32 & 0.07 & 0.17 & 0.54 & 0.32 \\
Pomacentridae & 1.98 & 2.99 & 2.43 & 2.47 & 2.35 & 3.41 & 3.68 & 3.31 \\
Pseudeochromidae & 0.00 & 0.00 & 0.00 & 0.00 & 0.00 & 0.00 & 0.02 & 0.00 \\
Scaridae & 0.32 & 0.22 & 0.39 & 0.47 & 0.34 & 0.32 & 0.34 & 1.27 \\
Scorpaenidae & 0.02 & 0.05 & 0.15 & 0.02 & 0.00 & 0.00 & 0.00 & 0.02 \\
Serranidae & 0.44 & 0.20 & 0.25 & 0.27 & 0.34 & 0.22 & 0.42 & 0.47 \\
Siganidae & 0.17 & 0.07 & 0.15 & 0.02 & 0.00 & 0.00 & 0.02 & 0.00 \\
Synodonthidae & 0.00 & 0.00 & 0.05 & 0.00 & 0.00 & 0.00 & 0.00 & 0.00 \\
Tetraodontidae & 0.00 & 0.02 & 0.07 & 0.02 & 0.00 & 0.00 & 0.20 & 0.02 \\
Trumpetfish & 0.00 & 0.05 & 0.00 & 0.00 & 0.00 & 0.07 & 0.00 & 0.00 \\
Zanclidae & 0.66 & 0.25 & 0.71 & 0.37 & 0.34 & 0.98 & 0.47 & 0.39 \\
\hline
\end{tabular}

Table 2. Diversity indeks of reef fish in Mesjid Raya District and Peukan Bada sub-districts in 2014-2018.

\begin{tabular}{|c|c|c|c|c|c|c|c|c|}
\hline \multirow{2}{*}{ Location } & \multirow{2}{*}{ Stations } & \multicolumn{6}{|c|}{ Diversity Index (H') } & \multirow{2}{*}{ Category } \\
\hline & & 2014 & 2015 & 2016 & 2017 & 2018 & Average & \\
\hline Mesjid & Site 1. Lhok Mee & 2.58 & 2.78 & 2.45 & 2.60 & 2.25 & 2.53 & Medium \\
\hline $\begin{array}{l}\text { Raya } \\
\text { sub- }\end{array}$ & $\begin{array}{l}\text { Site 2. Ahmad } \\
\text { Rhang Manyang }\end{array}$ & 2.63 & 2.55 & 3.05 & 2.61 & 1.81 & 2.53 & Medium \\
\hline district & $\begin{array}{l}\text { Site 3. Benteng } \\
\text { Inoeng Balee }\end{array}$ & 2.09 & 3.21 & 3.33 & 3.33 & 1.85 & 2.76 & Medium \\
\hline Peukan & Site 4. Pulau Tuan & 2.38 & 2.97 & 2.44 & 3.21 & 2.16 & 2.63 & Medium \\
\hline $\begin{array}{l}\text { Bada } \\
\text { sub- }\end{array}$ & $\begin{array}{l}\text { Site 5. Lhok } \\
\text { Keutapang }\end{array}$ & 0.00 & 3.10 & 3.01 & 2.16 & 2.12 & 2.08 & Medium \\
\hline \multirow[t]{3}{*}{ district } & $\begin{array}{l}\text { Site 6. Lhok Mata } \\
\text { Ie }\end{array}$ & 3.02 & 1.74 & 1.82 & 1.97 & 1.37 & 1.98 & Medium \\
\hline & $\begin{array}{l}\text { Site 7. Pulau Batee } \\
\text { Timur }\end{array}$ & 2.75 & 2.66 & 2.53 & 3.64 & 1.33 & 2.58 & Medium \\
\hline & $\begin{array}{l}\text { Site 8. Pulau Batee } \\
\text { Barat }\end{array}$ & 0.00 & 2.97 & 3.27 & 3.31 & 1.27 & 2.16 & Medium \\
\hline
\end{tabular}

Table 3. Evenness Index of reef fish in Mesjid Raya and Peukan Bada sub-districts in 20142018.

\begin{tabular}{|c|c|c|c|c|c|c|c|c|}
\hline \multirow{2}{*}{ Location } & \multirow{2}{*}{ Stations } & \multicolumn{6}{|c|}{ Diversity Index $\left(\mathrm{H}^{\prime}\right)$} & \multirow{2}{*}{ Category } \\
\hline & & 2014 & 2015 & 2016 & 2017 & 2018 & Average & \\
\hline Mesjid & Site 1. Lhok Mee & 0.44 & 0.48 & 0.42 & 0.45 & 0.66 & 0.49 & Depressed \\
\hline \multirow[t]{2}{*}{$\begin{array}{l}\text { Raya sub- } \\
\text { district }\end{array}$} & $\begin{array}{l}\text { Site 2. Ahmad } \\
\text { Rhang Manyang }\end{array}$ & 0.45 & 0.44 & 0.53 & 0.45 & 0.53 & 0.48 & Depressed \\
\hline & $\begin{array}{l}\text { Site 3. Benteng } \\
\text { Inoeng Balee }\end{array}$ & 0.36 & 0.55 & 0.57 & 0.57 & 0.54 & 0.52 & Unstable \\
\hline $\begin{array}{l}\text { Peukan } \\
\text { Bada sub- }\end{array}$ & $\begin{array}{l}\text { Site 4. Pulau } \\
\text { Tuan }\end{array}$ & 0.41 & 0.51 & 0.42 & 0.55 & 0.63 & 0.50 & Depressed \\
\hline
\end{tabular}




\begin{tabular}{llllllllll}
\hline \multirow{2}{*}{ Location } & \multicolumn{1}{c}{ Stations } & \multicolumn{7}{c}{ Diversity Index $\left(\mathrm{H}^{\prime}\right)$} & \multirow{2}{*}{ district } \\
\cline { 2 - 8 } & $\begin{array}{l}\text { Site 5. Lhok } \\
\text { Keutapang }\end{array}$ & 0.00 & 0.53 & 0.52 & 0.37 & 0.62 & 0.41 & Depressed \\
& $\begin{array}{l}\text { Site 6. Lhok } \\
\text { Mata Ie }\end{array}$ & 0.52 & 0.30 & 0.31 & 0.34 & 0.40 & 0.37 & Depressed \\
& $\begin{array}{l}\text { Site 7. Pulau } \\
\text { Batee Timur }\end{array}$ & 0.47 & 0.46 & 0.43 & 0.63 & 0.39 & 0.48 & Depressed \\
& $\begin{array}{l}\text { Site 8. Pulau } \\
\text { Batee Barat }\end{array}$ & 0.00 & 0.51 & 0.56 & 0.57 & 0.37 & 0.40 & Depressed \\
\hline
\end{tabular}

Table 4. Dominance index of reef fish in Mesjid Raya and Peukan Bada sub-districts in 20142018.

\begin{tabular}{|c|c|c|c|c|c|c|c|c|}
\hline \multirow{2}{*}{ Location } & \multirow{2}{*}{ Stations } & \multicolumn{6}{|c|}{ Dominance Index (C) } & \multirow{2}{*}{ Category } \\
\hline & & 2014 & 2015 & 2016 & 2017 & 2018 & Average & \\
\hline Mesjid & Site 1. Lhok Mee & 0.11 & 0.08 & 0.16 & 0.13 & 0.13 & 0.12 & Low \\
\hline Raya & Site 2. Ahmad & 0.09 & 0.13 & 0.06 & 0.15 & 0.25 & 0.14 & Low \\
\hline $\begin{array}{l}\text { sub- } \\
\text { district }\end{array}$ & $\begin{array}{l}\text { Rhang Manyang } \\
\text { Site 3. Benteng } \\
\text { Inoeng Balee }\end{array}$ & 0.20 & 0.05 & 0.06 & 0.06 & 0.21 & 0.12 & Low \\
\hline \multirow{5}{*}{$\begin{array}{l}\text { Peukan } \\
\text { Bada } \\
\text { sub- } \\
\text { district }\end{array}$} & Site 4. Pulau Tuan & 0.12 & 0.07 & 0.12 & 0.09 & 0.17 & 0.11 & Low \\
\hline & $\begin{array}{l}\text { Site 5. Lhok } \\
\text { Keutapang }\end{array}$ & 0.01 & 0.06 & 0.09 & 0.27 & 0.15 & 0.12 & Low \\
\hline & $\begin{array}{l}\text { Site 6. Lhok Mata } \\
\text { Ie }\end{array}$ & 0.06 & 0.30 & 0.35 & 0.27 & 0.35 & 0.27 & Low \\
\hline & $\begin{array}{l}\text { Site 7. Pulau } \\
\text { Batee Timur }\end{array}$ & 0.10 & 0.11 & 0.17 & 0.03 & 0.45 & 0.17 & Low \\
\hline & $\begin{array}{l}\text { Site 8. Pulau } \\
\text { Batee Barat }\end{array}$ & 0.00 & 0.08 & 0.06 & 0.05 & 0.42 & 0.12 & Low \\
\hline
\end{tabular}

\section{KESIMPULAN}

Hasil penelitian menunjukkan bahwa total spesies yang ditemukan pada perairan Aceh Besar selama tahun 2014-2018 sebanyak 115 spesies yang masuk kedalam 39 famili. Secara temporal kelimpahan ikan pada perairan Aceh Besar dari tahun 20142018 mengalami fluktuatif yang cukup tinggi. Perairan Kecamatan Mesjid Raya memiliki nilai kelimpahan ikan karang yang lebih rendah dibandingkan dengan perairan Kecamatan Peukan Bada. Hasil rata-rata nilai indeks ekologi ikan karang di Kecamatan Mesjid Raya dan Peukan Bada tahun 20142018 tidak memiliki perbedaan yang signifikan. Analisis indeks keanekaragaman ikan karang pada kedua lokasi digolongkan dalam kategori keanekaragaman sedang. Nilai indeks keseragaman ikan karang yang diperoleh dari kedua lokasi digolongkan dalam kategori komunitas yang tertekan. Perhitungan indeks dominansi ikan karang keduanya termasuk dalam kategori dominansi rendah.

\section{UCAPAN TERIMAKASIH}

Penulis juga mengucapkan terimaksih yang setinggi-tingginya kepada ODCUnsyiah yang telah mendukung penuh hingga penelitian ini terlaksanakan dengan 
baik. Selain itu penulis juga mengucapkan terimaksih kepada Reef Check Indonesia. Yayasan Lamjabat Aceh dan semua pihak yang telah membantu proses pengambilan data sehingga tulisan ini dapat selesai dengan semestinya.

\section{DAFTAR PUSTAKA}

Allen, G.R., R. Steene, P. Humann, \& N. Deloach. 2003. Reef fish identification tropical pacific. Australia New World Publications. Australia. 457 p.

Bryant, D., L. Burke., J. McManus, \& M. Spalding. 1998. Reefs at risk: a mapbased indicator of threats to the world's coral reefs. World Resources Institute. Washington. $60 \mathrm{p}$.

Edrus, I.N., S.W. Wijaya, \& I.E Setyawan. 2013. Struktur komunitas ikan karang di perairan Pulau Raya. Pulau Rusa. Pulau Rondo dan Taman Laut Rinoi dan Rubiah Nanggroe Aceh Darussalam. J. Lit. Perikanan. Ind., 19(4): 175-186.

http://doi.org/10.15578/jppi.19.4.2013 .175-186

English, S.C., Wilkinson, \& V. Baker. 1994. Survey manual for tropical marine resources. Australian Institut of Marine Science. Townville. 406 p.

Halford, A.J., D.A. Cheal, J. Ryan, \& D.M. Williams. 2004. Resilience to largescale disturbance in coral and assemblages on The Great Barrier Reef. Ecology. Australia. 1892-1905 pp.

Hieske, E. \& R. Myers. 2001. Reef fishes of the world. Harper Collins Publishers. Princeton University Press. Princeton. $400 \mathrm{p}$.

Hill, J. \& C. Wilkinson. 2004. Methods for ecological monitoring of coral reefs: A Resource for Managers. ver 1 . Australian Institute of Marine Science. Townsville. 123 p.

Johnson, C.G.P., M. Teichberg, V.N Bednarz, A. Gärdes, J.P Heiden, M.
Lukman, S. Miñarro, H. Kegler, L. Weiand, C. Wild, H. Reuter, \& S.C.A. Ferse. 2018. Spatio-temporal patterns in the coral reef communities of the Spermonde Archipelago. 20122014. II: Fish Assemblages Display Structured Variation Related to Benthic Condition. Frontiers in Marine Science, 36(5): 1-15. http://doi.org/10.3389/fmars.2018.000 36

Krebs, C.J. 1989. Ecological methodology. NewYork. NY Harper and Row Publishers. $645 \mathrm{p}$.

Kuiter, R.H. \& T. Tonozuka. 2001. Pictorial guide to Indonesian reef fishes. part 14. Zoonetics. Seaford Vic 3198. Australia. $622 \mathrm{p}$.

Madduppa, H. 2006. Kajian ekobiologi ikan kepe-kepe (Chaetodon octofasciatus) BLOCH 1787) dalam mendeteksi kondisi ekosistem terumbu karang di Pulau Petondan Timur. Kepulauan Seribu Jakarta. Institute Pertanian Bogor. Bogor. 64 pp.

http://repository.ipb.ac.id/handle/1234 56789/9410

Muniaha, H., A.I. Nur, \& Rahmadani. 2016. Studi kelimpahan ikan karang berdasarkan kondisi terumbu karang di Desa Tanjung Tiram Kabupaten Konawe Selatan. J. Manajemen Sumberdaya Perairan, 2(1): 9-19. http://ojs.uho.ac.id/index.php/JMSP/is sue/view/2491

Nasir, M., M. Zuhal, \& M. Ulfah. 2017. Struktur Komunitas Ikan Karang di Perairan Pulau Batee Kecamatan Peukan Bada Kabupaten Aceh Besar. Bioleuser, 1(2): 76-85.

http://jurnal.unsyiah.ac.id/bioleuser/ar ticle/view/9079/7153

Octavina, C., Z.H Asri, S. Purnawan, \& M. Ulfah. 2018. Coral bleaching Percentage in Krueng Raya Waters. Aceh Besar. International $J$. of Sciences: Basic and Applied (IJSBAR), 40(2): 116-123. 
https://www.gssrr.org/index.php/Jour nalOfBasicAndApplied/article/view/9 140/4098

Odum, E.P. 1993. Fundamentals of ecology. W.B. Saunders Company. Philadelphia. London. Alih Bahasa oleh: Samingan T. dan B. Srigandono. Gajah Mada University Press. Yogyakarta. 574 p.

Rudi, E., S.A Elrahimi, T. Kartawijaya, Y. Herdiana, F. Setiawan, S.T. Pardede, S. Campbell, \& J. Tamelander. 2009. Reef fish status in northern Acehnese reef based on management type. Biodiversitas, 10(2): 88-93. https://doi.org/10.13057/biodiv/d1002 06

Rudi, E. \& I. Muchlisin. 2010. Ikan karang perairan Aceh dan sekitarnya.
Penerbit Lubuk Agung. Bandung. 216 p.

Rudi, E. \& N. Fadli. 2012. Komunitas ikan karang herbivora di Perairan Aceh Bagian Utara. Depik, 1(1): 37-44. https://doi.org/10.13170/depik.1.1.25

Ulfah, M., C. Yolanda, S. Karina, S. Purnawan, \& S. Agustina. 2018. Perbandingan tutupan karang keras sebelum. saat dan sesudah pemutihan karang di Perairan Kreung Raya. Aceh Besar. J. Ilmu dan Teknologi Kelautan Tropis, 10(3): 739-745. http://doi.org/10.29244/jitkt.v10i3.21 974

Received :22 September 2019

Reviewed :23 January 2020

Accepted : 05 April 2020 
